\title{
GCU
}

Glasgow Caledonian

University

University for the Common Good

\section{A balancing act: a grounded theory study of the professional judgement of child protection social workers}

Kettle, Martin

Published in:

Journal of Social Work Practice

DOI:

$10.1080 / 02650533.2018 .1438997$

Publication date:

2018

Document Version

Author accepted manuscript

Link to publication in ResearchOnline

Citation for published version (Harvard):

Kettle, M 2018, 'A balancing act: a grounded theory study of the professional judgement of child protection social workers', Journal of Social Work Practice, vol. 32, no. 2, pp. 219-231.

https://doi.org/10.1080/02650533.2018.1438997

\section{General rights}

Copyright and moral rights for the publications made accessible in the public portal are retained by the authors and/or other copyright owners and it is a condition of accessing publications that users recognise and abide by the legal requirements associated with these rights.

Take down policy

If you believe that this document breaches copyright please view our takedown policy at https://edshare.gcu.ac.uk/id/eprint/5179 for details of how to contact us. 


\title{
A Balancing Act- A Grounded Theory Study of the Professional Judgement of Child Protection Social Workers
}

\author{
Author \\ Dr Martin Kettle \\ Senior Lecturer \\ Glasgow Caledonian University \\ Cowcaddens Road \\ Glasgow \\ G4 0BA \\ Telephone (+44) 01413318819 \\ Email: martin.kettle2@gcu.ac.uk
}

\begin{abstract}
The perspectives of social workers working to protect children are under-represented in the literature. This study, based on 22 in-depth interviews with social workers, adopts a grounded theory methodology. The policy context for child protection practice is outlined and analysed. This study then looks at how information, responsibility and in particular anxiety are transacted between social workers and other professionals, with anxiety being implicit in other aspects. Further, this study found that social workers negotiated a range of delicate balances. This paper focuses on two elements of the findings, namely, 'closeness- distance', and 'power overpower together'. If social workers became too close to families there was a risk of
\end{abstract}


losing perspective. If social workers were too distant engagement proved difficult. Social workers aspired to share power with families, but frequently exerted power over them. The delicacy of the balances negotiated by social workers leads to a powerful analogy of social workers as tightrope walkers, and strategies to seek balance are identified. The implications for practice are explored. More attention needs to be paid to the internal mental processes of social workers, a cautious approach should be taken to rational-technical solutions and social workers need to be better prepared to respectfully challenge other professionals.

Key Words: Child Protection; Grounded Theory, Decision Making, Social Work Practice 
Balance, like all our fundamental things, is something we can find, keep, lose and use; it is something we often want (Philips, 2010, p. xi).

\section{Introduction}

This paper seeks to explore this complex decision making environment and the 'work' in child protection work from the perspective of the social worker, which, as a number of commentators (Ferguson, 2010, 2016; Stanford, 2010; White, 2011) have noted, is under-emphasised in the literature. The paper will draw on one aspect of the writer's doctoral research (Kettle, 2015) a constructivist grounded theory (Charmaz, 2006, 2013) of child protection social work in Scotland and which drew on 22 indepth interviews with social workers. However, it will also draw on more recent work (for example, Featherstone et al., 2014, 2016; Shlonsky and Mildon, 2017), which continues to engage critically with front line child protection practice with families. It will be argued that central to the process of judgement and decision making are a number of delicate balances.

The paper will begin by placing the study in its Scottish context. It will be argued that the different policy drivers that impact upon child protection can be in tension and that social workers have to negotiate these tensions as part of their work to protect children. It will then turn to an exploration of the findings from the study, and three dimensions of the core category of balancing will be explored, namely interprofessional transactions, power over- power together and closeness-distance.

\section{Scottish Context}

It is necessary to place this study in its Scottish context, which shares a lot of similarities with other Anglophone jurisdictions (Lonne et al, 2008; Stafford et al., 
2011) but has a number of important differences. There are three main aspects, namely child protection reform, the reform of social work and Getting it Right for Every Child (GIRFEC). In 2002, following a national audit and review of child protection, the report "It's Everyone's Job to Make Sure I'm Alright" (Scottish Executive, 2002) was published with the title chosen to stress the broader corporate responsibility for child protection. However despite this broader responsibilty, social workers and their decision-making remained central. "Outcomes for children were found to be highly dependent on social work doing well" (Scottish Executive, 2002, p. 11). In May 2003 the review into the death of Caleb Ness was published, (O'Brien et al., 2003) which found a series of systemic failures and led to the introduction of a programme of multi-agency inspections of services to protect children (HMIe, 2010; Care Inspectorate 2013). A further policy strand was the frequent issuing of guidance (See for example Scottish Government, 2012, 2014). As this paper was being written, the Scottish Government published a further review of the child protection system, entitled It's Still Everyone's Job to Make Sure I'm Alright (Scottish Government, 2017) the title of which emphasises continuity with the earlier review. This is very much a review of the child protection 'system' and makes a series of recommendations in relation to, for example the establishment of a National Child Protection Register, without setting out in any real detail how they will contribute to improved outcomes for children and families, and the voice of practice is silent throughout.

However, as well as child protection in general, social work as a profession has undergone significant scrutiny in its own right. The 21 st Century Review of Social Work, Changing Lives (Scottish Executive, 2006) concluded inter alia that a new approach to risk was required (Ritchie and Woodward, 2009) although it is a matter of 
dispute as to how far this new approach has been achieved (Clark and Smith, 2012). The Vision and Strategy for Social Services in Scotland (Scottish Government, 2015) follows the lineage of Changing Lives and reiterates some of the earlier exploration risk, in particular concerns that practice may become risk averse.

The nature of the work can lead to a workforce that is risk averse so it is necessary to create an environment which allows people to be innovative whilst also taking responsibility and being accountable should things go wrong. (Scottish Government, 2015, p.23).

The last strand of policy that is relevant for this paper is GIRFEC, the Scottish Government's broader change agenda for children's services, with its emphasis on early and effective intervention with children and families. The cautious view is that progress has been made (Scottish Government, 2010), but as yet there is little clear empirical evidence of its effectiveness. However tensions remain between an emphasis on meeting the needs of all children and ensuring the needs of the most vulnerable are targeted (Aldgate and Rose, 2009; Brandon et al., 2008; Buchanan, 2009). Principles of GIRFEC were enshrined in the Children and Young Persons (Scotland) Act (2014).

Bringing this discussion from the policy arena to direct practice, a report of inspection into child protection in Scotland published in 2013 found much to be optimistic about. For those children who were formally identified as in need of protection generally agencies were seen as working together effectively. However the, "overall picture in respect of children whose names were not on the Child Protection Register (CPR) was more complex and less encouraging" (Care Inspectorate, 2013, p. 10), and there were, amongst other issues, concerns identified about support from families being withdrawn too quickly once CPR registration was ended, and a lack of clarity about thresholds for intervention. 
Looking at this complex policy agenda through the eyes of the front line social worker, these inherent tensions have to be managed by front line social workers, who have to operate within a context of a fluid discourse about risk. Further, a recurring theme is the importance of decision points in the lives of children and their families, and the complexity of the context within which those decisions are made (Platt and Turney, Kettle, 2015). However, it leaves social workers still as central to the processes of protecting children, whilst at the same time making the context within which they operate more ambiguous. As Shlonsky and Mildon express it,

Each decision contains a degree of uncertainty and corresponding error, and these errors are compounded with each decision and across decision-makers in child-protection involved systems. One would be hard-pressed to find a more complex decision-making environment (Shlonsky and Mildon, 2017, p.112).

Understanding how social workers make sense of what they do is, it is argued, is even more important than ever, and it is to this central aspect that this paper will now turn.

\section{Methodology}

However, before proceeding further it is necessary to explore methodological issues. The research that this paper draws upon used grounded theory, a methodological approach first developed by Glaser and Strauss (1967) Grounded theory has a number of key characteristics, including a basis in symbolic interactionist concepts and an iterative process of data gathering and data analysis, with key components of theoretical sensitivity, constant comparison, theoretical sampling and theoretical saturation (Oktay, 2012; Charmaz, 2013). Within grounded theory the question of the engagement with the literature is a matter of considerable controversy (McGhee et al., 2007; Dunne, 2011; Thornberg, 2012). One view (Glaser, 1992) is that there should be no engagement with the literature prior to undertaking fieldwork because it may 
influence the findings of the study. In short it may lead to forcing. However, there are a number of arguments that run counter to this. They include the practical, ensuring that the study has not already been done, as well as the theoretical, including contributing to sensitizing concepts. The deciding argument for this research is that the idea that any researcher undertakes a study without some level of prior knowledge or ideas is simply unrealistic (Cutcliffe, 2000). This study is adopted a middle ground (Martin, 2006; Dunne, 2011), hence beginning with the exploration of context, rather than a review of the literature.

The study used 22 in-depth interviews with social workers, conducted during 2014, each of which was transcribed by the author for analysis. Following the grounded theory approach, interviews continued until saturation was reached, that is that no new themes were emerging (Glaser and Strauss, 1967). Ethical approval was granted by both the University where the author studied and the local authority where the social workers were employed.

\section{Findings}

What this study found was that in working to protect children social workers have to negotiate a series of delicate balances. They seek to find the balance between; the interests of children and adults; the past, present and future; investigation and relationship; getting too close and not getting close enough; and power over and power together. This paper will, for reasons of space, focus on the last two but firstly explore the issue of working relationships with other professionals. 
Inter-professional Transactions

Social workers working to protect children are extremely dependent upon their relationships, often extremely complex, with other professionals, and referring to inter-professional transactions seems particularly appropriate. Transaction comes from the Latin transigere, to 'drive through', and is defined by the Concise Oxford Dictionary as:

"1. An instance of buying or selling; the action of conducting business.

2. An exchange or interaction between people".

Although there is no formal buying or selling involved, the "business" is both a more tangible transaction, which is the flow of information, and a less tangible transaction, that is the transfer of anxiety and responsibility. The three key aspects can be represented diagrammatically. What is indicated is that although information and responsibility are shared, there is an additional factor that requires to be taken into consideration that is the flow of anxiety, and social workers perceptions are that they are the repository of the anxieties of other professionals to a significant extent.

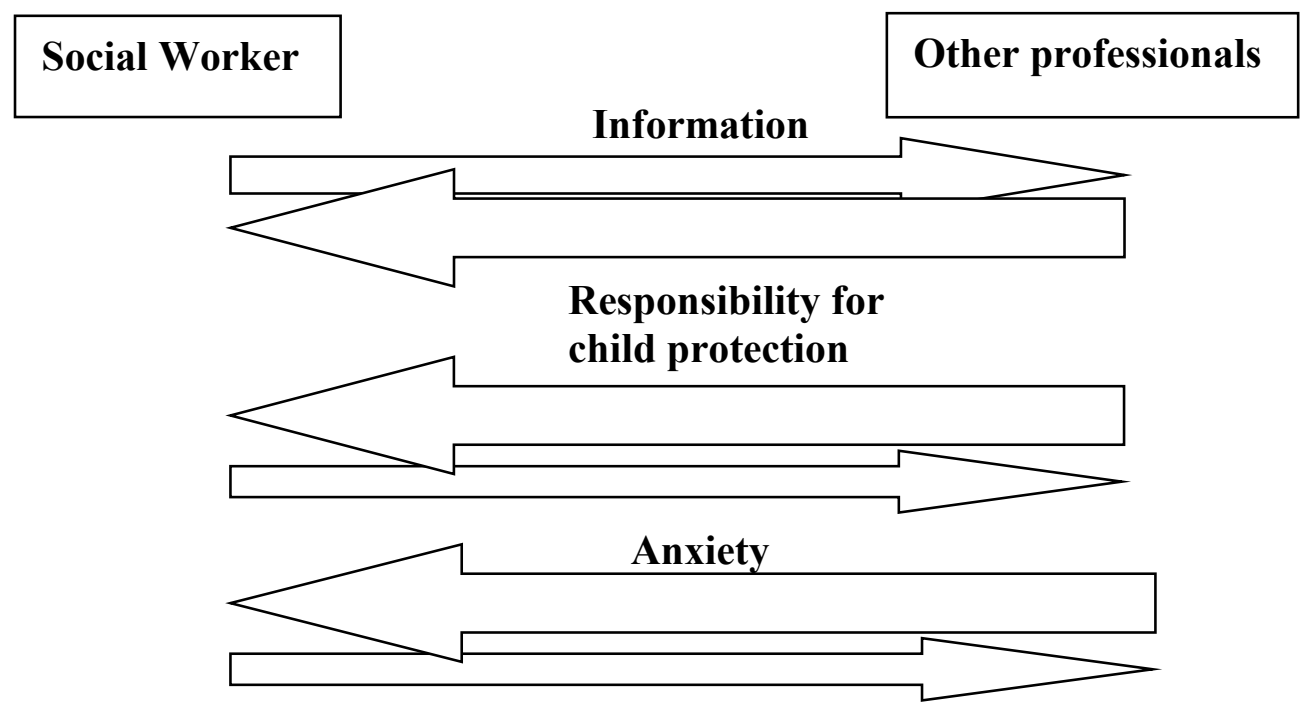

Figure 1. Inter- professional transactions- information, responsibility and anxiety. 
As this initial extract illustrates, children are, in part at least, more likely to be effectively protected by agencies working well together.

When you have done to the best of your abilities and you have other professionals next to you who are doing a very good job as well ..... you know that you have done everything possible to protect that child.

However, the transactions will have a number of variables depending upon the stage that the child protection process has reached and the particular circumstances of the family. Those variables will include the discipline and organisation that the professional comes from and the primary focus of that organisation's work, in particular whether it is with children or adults, and the level and nature of contact between the different organisations.

Co-operation can be seen as the cornerstone of inter-professional transactions. Improved co-operation and greater consistency were seen, at least in part, as being a consequence of recent progress on the delivery of the GIRFEC agenda. Co-operation was seen as being a two way process; there is a need not only to work in partnership but also a responsibility on social workers to work on partnership, as illustrated here.

Since I have started here that is something that I have always strived to do to have good working relationships with other agencies...if you add it all together then you get a fuller picture, but no-one's going to know everything.

From the perspective of the social workers, effective co-operation with colleagues in other agencies considerably enhanced work that was being done towards the protection of children. However, that was not always seen as being the case.

There was a pattern in the data that related to the exploration of difference. This started from an acknowledgement of difference with other professionals, based on 
training, values and organizational priorities. Whilst this is recognized as being a potential source of tension, an important strategy employed by social workers was to explore rather than ignore those differences, and to endeavour to find common ground with the overall aim of the protection of children.

It is now regarded as axiomatic that the protection of children is highly dependent upon an effective flow of information. However, information can be passed in different ways, sometimes in a way that is vague and indiscriminate. This can leave the worker with the feeling that what is really being passed is the anxiety and the responsibility for the situation, which may be explicit as illustrated here, by a social worker reporting a comment from a teacher, 'You know I'm really concerned, this is the type of one that will end up in the press'. One strategy adopted is to seek a greater degree of specificity or to point out that the passing of vague information does not help either organisation, or indeed the children who are the subject of concern.

(B)ut it is about saying to them, actually why are you telling me this? Because you have not helped me in any way, you have not helped the case in any way, you have just phoned about your anxiety.

This can be seen as trying to defuse that passage of anxiety, which can also resonate with the social worker's sense of their own responsibility for child protection, which will be explored further below.

Where the other profession has their primary responsibility to work with adults there was a continuum of responses. At one end information is shared freely and openly, and at the other end is a position where despite the best efforts of participants the information gathered is minimal, contributing to a heightening of anxiety. The location on that spectrum is conditional both on structural aspects, the relationships 
between the two agencies, as well as individual aspects of the working relationship between the professionals involved as well as some skilled negotiation on the part of social workers. There is an apparent paradox in that, for some participants at least, that confidence was most needed in the early stages of the career and growing into the role meant growing in confidence in the worker's ability, as well as making sense of the parameters of their responsibility.

Responsibility relates both to the level and nature of responsibility felt by participants. It also reflected participants' concerns about the nature and level of responsibility that participants perceived was placed upon them, and which was not always felt to be appropriate, particularly in relation to partner agencies' ability or willingness to challenge families. There is no doubt that there is a high level of responsibility felt by participants, particularly in the early stages of their career, and something for which they are not always fully prepared for by their training.

Probably when I first started my first thought or memories was that I thought everything was my responsibility....and that it was your responsibility to ensure that the situation didn't escalate or that kids didn't come to harm.

This leads into a discussion of the consequences of what are perceived to be an inappropriate placing of responsibility by partner agencies on social work. Participants were concerned about a number of strategies adopted by other professionals, including denial, minimization and ambivalence. Ambivalence in particular was related to agencies distancing themselves from initial concerns, leaving the social worker isolated and then being seen by the family as being the persecutor. This may leave the participant facing the difficult task of rebuilding the relationship with the family. 
An important example is in respect of responsibility and anxiety about children, what Reder and Duncan (2003) refer to as meta- communication. This can be seen as relating to anxiety, which, "runs like a vein throughout the child protection process" (Morrison 1997, p.196) This is also explored by Hughes (2009) who sees it as an organizational as well as an individual phenomenon, and that failure to contain anxiety can have a serious negative impact on the broader functioning of the organisation.

This section has explored the complexities of the context within which social workers have to work and will now turn to one of the key dimensions of the balancing act itself, namely that of closeness- distance.

\section{Closeness-distance}

In essence, getting too far away from families, becoming too remote, ran the risk that engagement would be ineffective in bringing about change, and getting too close ran the risk of losing perspective or becoming enmeshed in the family, with the potential consequence of children being left unprotected. This study identified strategies adopted by families and by social workers to manage distance. This initial extract illustrates the recognition of this dimension and the adoption of a conscious strategy by a worker to guard against prejudging the situation.

When you walk into a situation then you can very much get sucked into it and end up going down one road, whereas if you sit back and try and take the lead from the family and then ask sort of the right questions a very different situation can emerge.

It is possible to identify a number of strategies that families were able to utilise to manage the distance between themselves and professionals. At one end of the spectrum was hostility and aggression, which was to an extent seen by participants as 
part of the job, to be accommodated and worked through, and it was striking how normalised this was seen as being for workers. Participants identified a range of manifestations of hostility, from threats, shouting and swearing, harassment by frequent phone calls, including in one instance to a social worker's home number, and sometimes simply refusing to allow a worker to leave the home.

....but when I entered the house and everything seemed to be fine, and I had sat at the other end of the room, and they had locked the door and just taken it out on me, screaming abuse in my face, calling me names and I felt really scared at that time.

As well as hostility, a pattern emerged of experiencing point blank refusal by families to engage. However, a lack of co-operation was not always as explicit as that point blank refusal, and other strategies that were identified included a failure to keep appointments, or declining to comply with other elements of the plan for intervention, for example, working with drug and alcohol services.

Failure to co-operate was sometimes manifested as dishonesty in order to prevent the social worker gaining a complete picture, with a consequential raising of anxiety for the social worker. Related to this, the importance of the strategy of managing the flow of information as a means of regulating distance was clearly recognised. A pattern emerged of families giving different accounts to different professionals, with a consequence of the importance of inter-professional transactions.

I think that's a real issue that a lot of families seem to think that they can tell someone one thing and tell someone something else ......and it's really positive that there's good relationships that we can discuss any concerns that we have and you can get a very rounded picture.

Families did not always seek to increase the distance to the worker, and balance was seen as being in place when cooperation was forthcoming, and is important to stress that families often wanted to reduce distance because they were seeking help and that 
they were co-operating as a consequence of this. Participants also experienced a range of strategies to reduce distance, and perhaps paradoxically, participants experienced hostility and aggression in this sense as well, sometimes feeling dragged down by it, but in direct contrast was the reduction of distance through flattery.

A lot of these families were very skilled at using social workers... and they would say things like.... "you're the best social worker we've ever had" so that you'd not rock the boat with them.

Finally however, it is important to stress that there was a positive element to families reducing distance because they were seeking help and that they were co-operating as a consequence of this, and this extract is illustrative of a process of working through to achieve a working relationship.

.....they [families] seem to go through different phases and before long they're accepting of it, the hostility goes away, they become accepting and it's not long after that they can get on with you in a working context .... and before you know it you've got a working relationship with the family.

Turning now to strategies adopted by workers to manage distance, a significant concern was the importance of retaining perspective and reflection was a key strategy, particularly where neglect was an issue. It was facilitated through a number of different mechanisms, sometimes as a solo enterprise, sometimes through formal supervision and sometimes through less formal discussion with peers. Related to that was the adjustment of pace, that is adjusting what is being expected of families and the pace at which change is expected of them.

...but I know that one bit of work that I felt was really quite successful was ...building that rapport with that mum, and recognising her vulnerabilities with it and probably taking that far slower approach, and that actually did work much more effectively.

Turning now to maintaining distance, there was a pattern of this flowing from the first encounter, and setting the tone for the relationship that follows on. 
I think that one of the best pieces of advice that I was given ... was really about being as honest and upfront with families that you are working with from the very outset.

Revisiting that initial honesty over the course of working with a family was seen as a strategy for regulating the distance and maintaining it at a level that allowed for effective working relationships.

Two main patterns were identified around the reduction of distance. Firstly, there was challenging families, as illustrated by this very detailed exploration by one of the participants, as encapsulated in the repetition of the phrase, "strip it right back".

What I will do is that I will strip that right back. I said, "I'm not asking what she done, I'm asking what you done" and I will do that and I will strip it right back.

The strategy of last resort for most participants was the use of legal powers, for example the seeking of a Child Protection Order or making a referral to the Reporter in order to seek grounds for a compulsory supervision requirement. Finally, there was the strategy of getting close as a way of supporting families, although participants were sometimes able to recognise the risk of becoming enmeshed.

In concluding this section it is clear that the consequences of being too remote or too close are both that children may be left unprotected. This paper will now turn to an exploration of power and authority and the use of 'good authority' which remains a central concern of child protection practice (Ferguson, 2011).

Power

The issue of power is never far from the surface in child protection work, particularly during the initial phase of contact with families, and managing that power was a significant concern for participants. This section will explore the property of power 
over-power together, and draws on Tew's $(2003,2006)$ typology of power to inform the analysis.

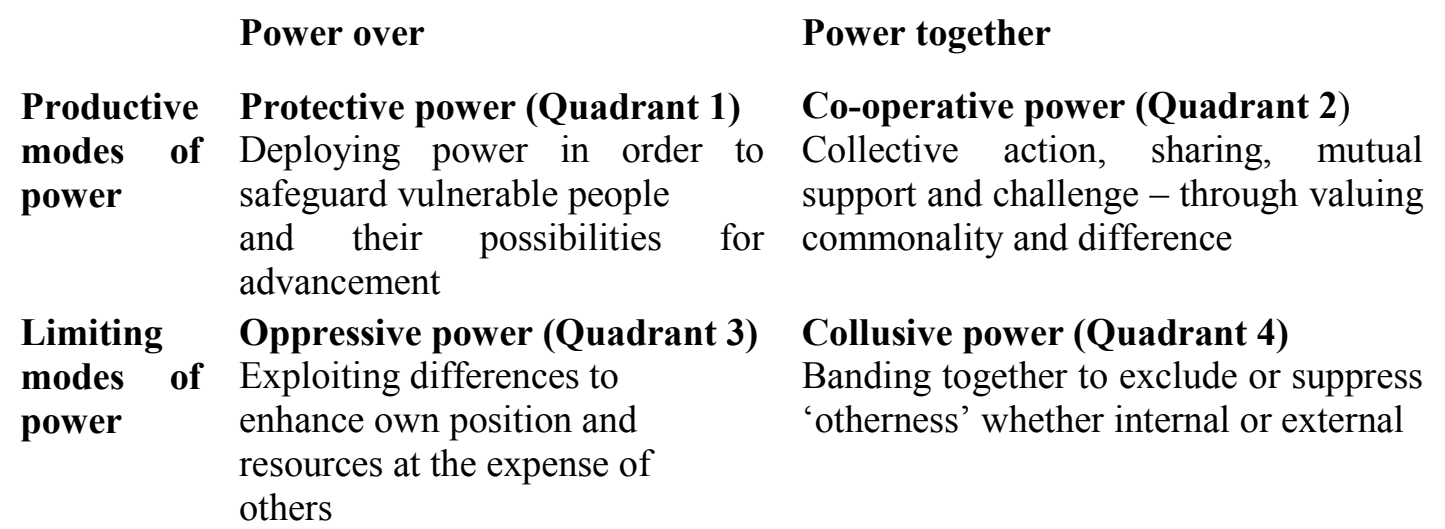

Table1. Tew's typology of power

Although Tew was not writing about child protection directly, what makes his typology particularly apposite is the differentiation between power being used over and power being used with others, in this instance families.

Whilst there is a focus on the exercising of power and authority, there was pattern in the data that recognised that this was not static, and was subject to shifting influences. Power was partly inherent in the role of social worker, but in part it was something that required to be developed. This extract from a social worker who had been qualified only two years demonstrates a nuanced understanding of the power dynamics.

I suppose that there is a point where you need to tell families what they need to do, and sometimes people are resistant to you, and they are not going to go through that process with you.....but I think that it is about building the relationship so that people are more willing to work with you and you are more likely to make progress.

A key element of exercising authority is the fulfilling of the legal mandate, which may well lead to being subject to repeated scrutiny from the courts and Children's 
Hearings, a scrutiny that increased awareness of accountability and reduced perceptions of power.

We haven't got a lot of power when it comes down to it, we need to get the court or children's hearing to do a, b or c, however the amount of times that you will maybe go out to a family ... and families seem to think that you have a lot more power than you actually have.

What is referred to "Quadrant 2- Quadrant 3" is a complex property and relates to moving between the two quadrants of Tew's typology, addressing the exercise of power on an apparently voluntary basis, but potentially slipping into potentially oppressing families. A recurring theme was that there is some kind of hinterland between the legal exercise of authority and working with people on a voluntary basis. A pattern emerged of negotiating a fine line between the reality of exercising power, referred to by one participant as 'the wagging the finger stuff, and the power that was ascribed to them by families, preferring to achieving co-operation not by any explicit threat of the use of power, but by the perception of that by the parents.

Interviewee: I have also advised the family that this, this is voluntary, we are asking you do this, your co-operation would be helpful....however it is not legally required....

Interviewer: Right, so then what comes after the however?

Interviewee: In all honesty, and I do think that this is a bit of a paradox, then it is about having to explain to families that this is how co-operation is viewed later on in the process.

A pattern that emerged very strongly for participants was that they did not feel suitably equipped when they qualified, and therefore needed to work on both developing the authority and coping with the emotional impact of the work. Much of the learning had to be acquired on the job, and that this process of acquisition was a key part of growing into the role, with self-doubt never far away.

I don't know if I've developed the authority- it's just looking at the overall needs of the child, and part of that is that when you are dealing with protecting a child, you've got no choice but to assert your authority. 
However, whilst assertiveness is crucial to the process of developing authority it was far more complex than that, so again there was a paradox of growing knowledge 'Yes. I'm more certain in my practice, if that makes sense, but I'm less certain sometimes about outcomes'.

Another source of confidence was knowledge, which was sub-divided into formal and informal knowledge. Formal knowledge was training in terms of training events or certificated training, whereas informal knowledge was, for example, a consequence of modelling the behaviour of others, simply learning from those around them. As explored above, the exploration of power from participants underlines that it does not flow in one direction, and that families and parents have strategies in relation to power open to them. Further, there are a range of limits that comes from checks and balances within the child protection system, but one of the key limiting factors in relation to authority and power was being aware of the potential of the power that was held by workers, but also about becoming aware over time of the limits, in particular a growing realization that it is not possible to be in the lives of children all the time, and moving on from the initial feeling of responsibility with a consequence of frustration at relative impotence, 'it is an uphill struggle most of the time, trying to make change, trying to make a difference in families- it is just so difficult'.

So as well as a growing sense of authority, there was also a growing realization of the limits of the power that came with the role. Further, there was a self-doubt that came from not feeling able to influence the situation that children were living in, but also a sense of not being able to walk away, of still feeling responsible.

Interviewee: Sometimes there is nowhere to go.

Interviewer: Yeah

Interviewee: You feel stuck 
Interviewer: So what do you do when you feel stuck?

Interviewee: (laughs) You try again

Interviewer: You try again

Interviewee: That's all you can do.

What this section has done is to explore the nuances of power and authority that are inherent in the role of protecting children, and this paper will now turn to a discussion of the implications.

\section{Discussion}

A small-scale qualitative study of this nature does have limitations, in particular the lack of generalisability, and as a consequence there are limits to the claims that can be made from it (Charmaz, 2013). Despite this, it is argued that useful insights for practice may be drawn.

The key message from this research for direct is that child protection practice it is a balancing act, and that there is a need to think beyond dualisms. Further, balance is something to be worked towards, both in the achievement and in the maintenance, rather than an ideal state or an end result to be achieved. The analogy of the tightrope walker, or funambulist, is central. Funambulist comes from the Latin for "rope dancer", and implies a greater level of agility than merely a tightrope walker. Secondly, watching funambulists in action it is striking that they are never entirely still, and that the process of keeping balance requires frequent, minor adjustments of arms and legs, in order to compensate for things like minor movements in the rope or wind. So the maintenance of balance is very much a dynamic, intuitive practice that requires the participant being focused on the activity in hand. 
It would be antithetical to the thrust of the theory that has been developed here, with its emphasis on the complexities and dynamic nature of the process of protecting children, to suggest some kind of checklist. However, it is argued that the theory itself has potential to be used as a lens through which it is possible to examine practice. In that sense it encourages both the development of relationship based approaches, a critical attitude to those approaches and a consideration of the importance of power (Ruch, 2009).

It is important to stress both the dynamic nature of child protection activity and the holistic nature of the theory, which as presented here puts professional judgement at the heart of the enterprise of protecting children and points to an emphasis on the development of practice wisdom and what Carr (2011) refers to as virtue ethics.

Further, there is a need to accept, understand and explore what Polanyi refers to as the tacit dimension, with his emphasis on not merely looking at things, but 'dwelling in them' (Polanyi, 1966, p.18), and in this sense this reinforces and develops Howe's (1996) argument for depth rather than surface explanations. The theory in its totality also suggests a cautious attitude towards technical- rational solutions, such as assessment tools. This paper does not argue against their use but, as with the funambulist's pole, they should be regarded as necessary, but not sufficient, for effective practice. They should not be viewed as a replacement for the core activity of the development of, and opportunities to reflect upon, key interpersonal skills such as relationship building (Ruch et al., 2010) and effective communication (Koprowska, 2014). This paper also points towards an emphasis on the process of child protection as well as the outcome. For example, in terms of the phrase that has cropped up repeatedly for participants, "going child protection" it points to a need to emphasise 
and explore the going as much as, if not more than, the child protection. A position "that I am only here for the child" seriously underplays an understanding of children and young people as relational and runs the risk of decontextualizing them (Featherstone et al., 2014). Significantly, the findings stress the importance of supporting children through the mechanism of supporting their parents.

In relation to closeness-distance, this study has identified that there are a range of strategies that are potentially adopted both by social workers and by families to increase, maintain or reduce the distance between them, and it sensitises workers to be alert to the potential for hostility and aggression, as well as the possibility of families not always being honest with them. Further, it suggests that social workers should assume a critically reflective attitude to co-operation from families, and they should be encouraged to be mindful of the possibilities of both superficial compliance and the risk of being drawn too far into the lives of families.

What this study encourages social workers to consider, perhaps more than anything else, is the complexity of the use of power in child protection social work. Specifically, this study indicates that the issue of power in the relationship with families warrants detailed consideration. There is clearly recognition that the exercise of power is an integral, even inevitable, part of child protection social work. However, the legal mandate, whilst important, represents only part of the basis of that power.

\section{Conclusion}

The complexity of the balancing acts that social workers are asked to undertake gives rise to three main implications. Firstly, there should be a greater level of appreciation 
and understanding when, for whatever reason, balance is lost. Secondly, a key question is how structures can support social workers and other professionals in the undertaking of balancing. Thirdly, understanding of the different components of balance should be integral to the education and training of social workers working in child protection.

Protecting children is, in essence, about keeping the child at the centre of concerns, whilst at the same time understanding the complexity of the context within which they are living. As with the funambulist, the task of the social worker working to protect children is about knowledge, skill, intuition, practice and tenacity, mixed with a degree of courage. In short, it is a balancing act. 


\section{References}

Aldgate, J. and Rose, W. (2009). Assessing and Managing Risk in Getting it Right for Every Child. Edinburgh: Scottish Government.

Brandon, M., Belderson, P., Warren, C., Howe, D., Gardner, R., Dodsworth, J. and Black, J. (2008). Analysing Child Deaths and Serious Injury Through Abuse and Neglect: What Can We Learn? A Biennial Analysis Of Serious Case Reviews 2003-2005. London: Department for Children, Schools and Families.

Buchanan, G. (2009). Child protection and risk - the relationship between risk assessment and Getting It Right For Every Child (GIRFEC): Review of national child protection guidance. Edinburgh: Scottish Government.

Care Inspectorate (2013) Child Protection Services: Findings of Joint Inspections 2009-12. Dundee: Care Inspectorate.

Carr, D. (2011). Virtue, character and emotion in people professions: Towards a virtue ethics of interprofessional conduct. In L. Bondi, D. Carr, C. Clark \& C. Clegg (Eds.) Towards professional wisdom: Practical deliberation in the people professions, (pp. 97-110). Ashgate: Aldershot.

Charmaz, K. (2006). Constructing grounded theory: A practical guide through qualitative analysis. London: Sage.

Charmaz, K. (2013). Constructing grounded theory: A practical guide through qualitative analysis (2nd ed.). London: Sage.

Clark, C. and Smith, M. (2012). Changing lives: What is really changing for Scottish social work? European Journal of Social Work, 15, 313-329. doi: 10.1080/13691457.2010.543892

Cutcliffe, J. (2000). Methodological issues in grounded theory, Journal of Advanced Nursing, 31, 1476- 1484. doi: 0.1046/j.1365-2648.2000.01430.x

Dunne, C. (2011). The place of the literature review in grounded theory research, International Journal of Social Research Methodology, 14, pp. 111-124. Doi: $10.1080 / 13645579.2010 .494930$

Featherstone, B., White S. \& Morris K. (2014). Re-imagining child protection: Towards humane social work with families. Policy Press: Bristol.

Featherstone, B., Gupta, A., Morris, K. and Warner, J., (2016). Let's stop feeding the risk monster: Towards a social model of child protection, Families, Relationships and Society doi: $10.1332 / 204674316$ X14552878034622 
Ferguson, H. (2010). Walks, home visits and atmospheres: Risk and the everyday practices and mobilities of social work and child protection, British Journal of Social Work, 40, pp.1100-1117. doi: 10.1093/bjsw/bcq015

Ferguson, H. (2011). Child protection practice. Palgrave: London.

Ferguson, H., (2016). Researching social work practice close up: Using ethnographic and mobile methods to understand encounters between social workers, children and families. British Journal of Social Work, 46, pp.153-168. doi https://doi.org/10.1093/bjsw/bcu120

Glaser, B. (1992). Emergence vs. forcing: basics of grounded theory analysis. Sociology Press: Mill Valley, CA.

Glaser, B. and Strauss, A. (1967). The discovery of grounded theory. Aldine: New York.

Her Majesty's Inspectorate of Education (HMIe) (2010). How well are Scotland's children protected? HMIe: Edinburgh.

Howe, D. (1996). Surface and depth in social work practice. In N. Parton (Ed) Social work theory, social change and social work, (pp. 77-97). Routledge: London.

Hughes, L. (2009). The most important professional relationship. In L. Hughes and H. Owen (Eds) Good practice in safeguarding children: Working effectively in child protection, (pp. 237-246). Jessica Kingsley: London.

Kettle (2015) A balancing act: A grounded theory of child protection. Unpublished Professional Doctorate thesis, Glasgow Caledonian University

Koprowska J (2014). Communication and interpersonal skills in social work (4th edn) Learning Matters: Exeter.

Lonne, B., Parton, N., Thomson, J. \& Harries, M. (2008). Reforming child protection. Routledge: Abingdon.

McGhee, G., Marland, G., \& Atkinson, J. (2007). Grounded theory research: Literature reviewing and reflexivity. Journal of Advanced Nursing, 60, pp. 334-342. doi: $10.1111 / \mathrm{j} .1365-2648.2007 .04436 . x$

Morrison, T. (1997). Emotionally competent child protection organizations: Fallacy, fiction or necessity? In J. Bates, R. Pugh \& N. Thompson (Eds) Protecting children: Challenges and change, (pp 193-211). Arena: Aldershot.

O'Brien, S., McKinnon, M. \& Hammond, H. (2003). Report of the Caleb Ness inquiry, Edinburgh City Council: Edinburgh.

Oktay, J. (2012). Grounded Theory. Oxford University Press: Oxford. 
Philips, A. (2010). On Balance. Penguin: London.

Polyani, M. (1966). The Tacit Dimension. University of Chicago Press: Chicago.

Platt, D. and Turney, D. (2014). Thresholds for child protective interventions: a conceptual analysis, British Journal of Social Work, 44, pp. 1472-1490. doi: https://doi.org/10.1093/bjsw/bct007

Reder, P. \& Duncan, S. (2003). Understanding communication in child protection networks. Child Abuse Review, 12, pp. 82- 100. doi: 10.1002/car.787

Ritchie A. \& Woodward R. (2009). Changing lives: critical reflections on the social work change programme for Scotland. Critical Social Policy, 29, pp. 510- 532. doi: 10.1177/0261018309105182

Ruch, G. (2009). Identifying 'the critical' in a relationship-based model of reflection, European Journal of Social Work, 12, pp. 349- 362. doi: http://dx.doi.org/10.1080/13691450902930761

Ruch, G., Turney, D. \& Ward, A. (2010). Relationship-based social work: Getting to the heart of practice. Jessica Kingsley: London.

Scottish Executive (2002). It's everyone's job to make sure I'm alright: The audit and review of child protection in Scotland. Scottish Executive: Edinburgh.

Scottish Executive. (2006) Changing Lives. Scottish Executive: Edinburgh.

Scottish Government (2010). A guide to implementing Getting It Right for Every Child: Messages from pathfinders and learning partners. Edinburgh: Scottish Government.

Scottish Government (2015). The Vision and Strategy for Social Services in Scotland. Edinburgh: Scottish Government.

Scottish Government (201) It's still everyone's job to make sure I'm alright. Edinburgh: Scottish Government.

Shlonsky, A. \& Mildon, R. (2017) Assessment and decision making to improve outcomes in child protection. In M. Connelly, (Ed) Beyond the risk paradigm in child protection, (pp. 111-129). Palgrave: London.

Stafford, A., Parton, N., Vincent, S. \& Smith, C. (2011). Child protection systems in the United Kingdom: A comparative analysis, Jessica Kingsley: London.

Stanford, S. (2010) 'Speaking back' to fear: Responding to the moral dilemmas of risk in social work. British Journal of Social Work, 40, pp. 1065- 1080. doi:

https://doi.org/10.1093/bjsw/bcp156

Thornberg, R. (2012). Informed grounded theory, Scandinavian Journal of Educational Research, 56, pp. 243-259. doi: http://dx.doi.org/10.1080/00313831.2011.581686

Tew J. (2003) Social theory, power and practice. Palgrave: London. 
Tew J (2006) Understanding power and powerlessness: Towards a framework for emancipatory practice in social work. Journal of Social Work, 6, pp. 33-51. doi: $\underline{10.1177 / 1468017306062222}$

White, S. (2011). "Fabled uncertainty in social work" In L. Bondi, D. Carr, C. Clark \& C. Clegg (Eds.) Towards professional wisdom: Practical deliberation in the people professions, (pp. 171-185). Aldershot: Ashgate. 